\title{
Sternal malunion fixation using a Titanium Sternal Fixation System in a diabetic patient. The first of its kind in Scotland
}

\author{
Sanjeet Singh Avtaar Singh ${ }^{1}$, Massimo Capoccia ${ }^{1}$, Kamal Deep $^{2}$, Nawwar Al-Attar ${ }^{3}$ \\ ${ }^{1}$ Department of Cardiothoracic Surgery, Golden Jubilee National Hospital, Glasgow G81 4DY, UK. \\ ${ }^{2}$ Department of Orthopaedic Surgery, Golden Jubilee National Hospital, Glasgow G81 4DY, UK. \\ ${ }^{3}$ Scottish National Advanced Heart Failure Service, Golden Jubilee National Hospital, Glasgow G81 4DY, UK.
}

Correspondence to: Dr. Sanjeet Singh Avtaar Singh, Department of Cardiothoracic Surgery, Golden Jubilee National Hospital, Agamemnon Street, Glasgow G81 4DY, UK. E-mail: sanjeetsingh@nhs.net

How to cite this article: Singh SSA, Capoccia M, Deep K, Al-Attar N. Sternal malunion fixation using a titanium sternal fixation system in a diabetic patient. The first of its kind in Scotland. Vessel Plus 2017;1:242-5.

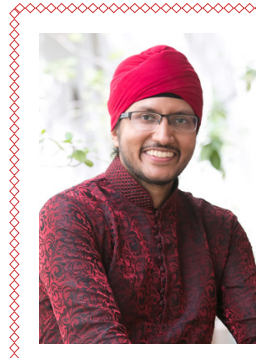

Mr. Sanjeet Singh Avtaar Singh, MBChB (Edin), MSc (Edin), MRCS (Edin), is a cardiothoracic research fellow who is currently the Cardiothoracic Advisory Group (CTAG) Audit Fellow based in Scotland at the Golden Jubilee National Hospital. He is currently pursuing his PhD at the University of Glasgow. His research interests surround primary graft dysfunction in heart transplantation.

\section{Article history:}

Received: 17 Jul 2017

First Decision: 5 Sep 2017

Revised: 5 Sep 2017

Accepted: 11 Sep 2017

Published: 28 Dec 2017

Key words:

Sternal fixation,

sternal dehiscence,

diabetes,

bilateral internal thoracic artery

\section{ABSTRACT}

Sternal non-union is a rare but serious complication post-sternotomy. It is defined as sternal pain with clicking, instability, or both for more than 6 months in the absence of infection and usually presents in an outpatient setting. It may result in multiple admissions to the hospital for surgical debridement and wound care therapies. Several risk factors have been identified in the literature but treatment options are limited. Proven benefits of increased stability and decreased incidence of non-union using the principles of rigid fixation have been described in other surgical specialties such as orthopaedic surgery. Employing this, the authors describe the first successful sternal non-union fixation using the Titanium Sternal Fixation System (DepuySynthes) in Scotland.

\section{INTRODUCTION}

A 54-year-old male was referred to our unit following a Non-ST elevation myocardial infarction. His past medical history included type 2 diabetes mellitus for which he was on oral hypoglycaemic agents and subcutaneous insulin. He underwent a coronary angiogram that revealed severe triple vessel disease in: License (https://creativecommons.org/licenses/by/4.0/), which permits unrestricted use, distribution, and reproduction in any medium, as long as the original author is credited and the new creations are licensed under the identical terms.

For reprints contact: service@oaepublish.com
}

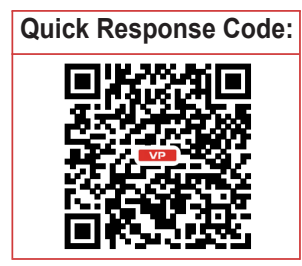


(1) the left anterior descending artery; (2) intermediate artery; (3) right coronary artery. The patient also had an occluded distal circumflex artery.

At the time of angiography, the patient had an estimated ejection fraction of about $35 \%$. He was referred to the care of the cardiac surgeons for consideration of coronary artery bypass grafting (CABG).

He successfully underwent a quadruple vessel bypass using a bilateral internal thoracic artery (BITA) technique. This involves using both internal thoracic arteries as a Y-graft and sequential anastomosis to the target vessel. The closure of his sternum was performed using stainless steel wires (USP size 6) in a modified Robicsek technique [Figure 1] given his history of diabetes. This involves placing stainless steel wires parasternally on both sides. The initial wire is passed via the manubrium through the second intercostal space, forming a ring. This is continued for the succeeding intercostal spaces. Transverse parasternal wires are then placed proximal to distally allowing horizontal and vertical stabilization. He was discharged on postoperative day 6 after satisfactory progression $^{[1]}$. On his journey home, the taxi he was involved in a near collision necessitating a sudden stop. He recalled an audible click on the tugging action of the seatbelt and noted increase movement in his sternum. He was referred following concerns of a nonhealing sternal wound that was treated conservatively in the community that was worst on lifting objects and affected his sleep.

\section{CASE REPORT}

He described abnormal clicking and movement of

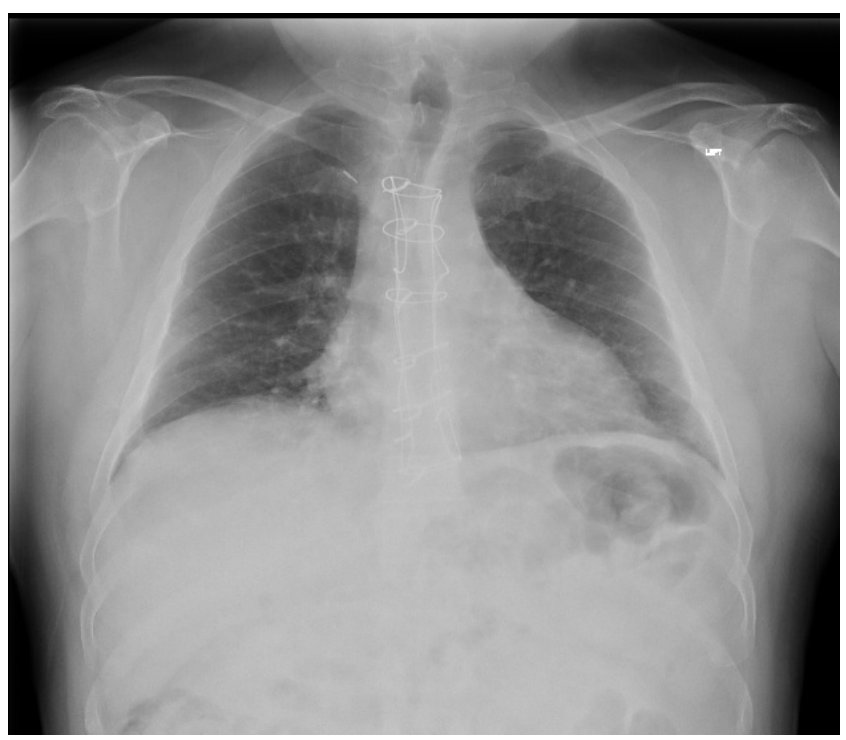

Figure 1: Chest X-ray showing sternal wires

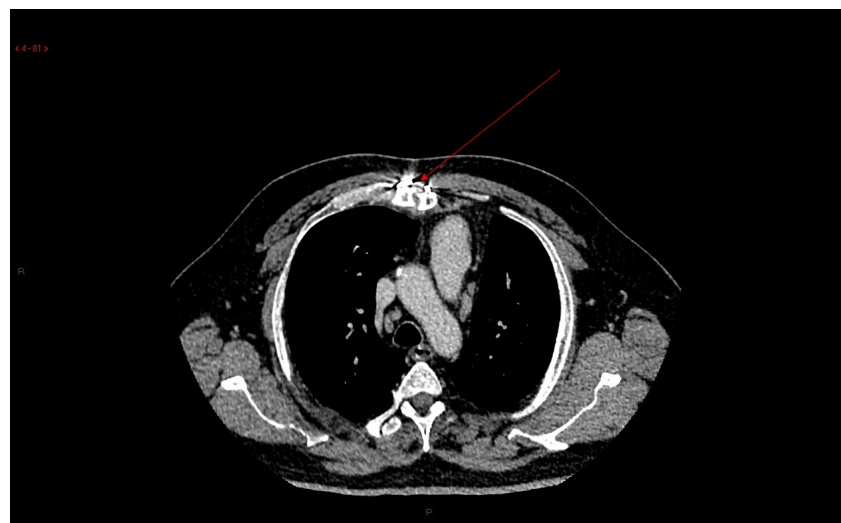

Figure 2: Computed tomography scan of thorax showing nonunion of sternum (red arrow - sternal malunion)

his sternum when turning in bed. There were no discharging sinuses as the skin had healed well. All other examination findings were normal.

His blood results revealed a $\mathrm{HbA} 1 \mathrm{c}$ of $110 \mathrm{mmol} / \mathrm{mol}$ (normal range 20-42) indicating poor glycemic control. All other blood results were within normal limits.

A computed tomography scan revealed noted the displacement of the two sternal edges with a midline defect confirming malunion of the sternum and he was consented for sternal fixation. He was also referred to a diabetologist for optimisation of his glycemic control [Figure 2].

\section{Procedure}

The patient was prepped and draped in standard fashion. A midline incision was made on the skin. The sternal wires were removed and sent for microbiology analysis. Further debridement of devitalised tissues was performed with no use of bone wax. A specimen of bone was sent for microbiology.

Using a depth gauge, the sternal edges adjacent to each rib was measured for placement of the plates. Sternal reducing forceps was then used to reduce the cranial and caudal ends of the sternum. A template was used to gauge the size and contours needed prior to shaping of the eventual plate using bending pliers and a rod cutter. Two other plates were inserted to provide satisfactory fixation of the sternum. Bone grafts from the patients iliac crest was used to enhance the osteosynthesis. The sternum was then irrigated with saline. The pectoral muscles were sutured using interrupted Vicryl sutures, with continuous Vicryl for the subcutaneous layer closure and skin using Monocryl. The patient was extubated in theatre and taken to the wards.

Postoperatively, the patient recovered well with 
minimal oral opioids and was discharged home on postoperative day 3 [Figure 3].

Microbiology results revealed inflamed fibrous tissue with a fibrinous reaction from the sternal debridement and no signs of infection or malignancy.

He was seen at the routine follow-up clinic 6 weeks and 1 year postoperatively with no further complaints of pain.

\section{DISCUSSION}

Since the advents of the SYNTAX trial (2009) ${ }^{[2]}$, CABGs have been the mainstay of treatment of triple vessel diseases involving the left main stem as it had a lower rate of major adverse cardiac or cerebrovascular event at 1 year. Most CABG patients across the UK (90\%) receive a "standard" operation with a single internal thoracic artery and vein grafts for revascularisation with excellent postoperative outcomes ${ }^{[3]}$. Progressive vein graft failure however is inevitable in these groups ${ }^{[4]}$. A meta-analysis by $\mathrm{Yi}$ et al. ${ }^{[5]}$ highlighted that the benefits of BITA that continued to increase with duration of follow-up with freedom from redo surgery and survival[ ${ }^{[5]}$. A study by Nasso et al. ${ }^{[6]}$ showed the superiority of a dual arterial technique over a single arterial graft technique at 2 years.

Critics of BITA however highlight its limitation with the theoretical increased risk of sternal wound infections due to the devascularisation of the sternum. Grossi et al.[ ${ }^{[7]}$

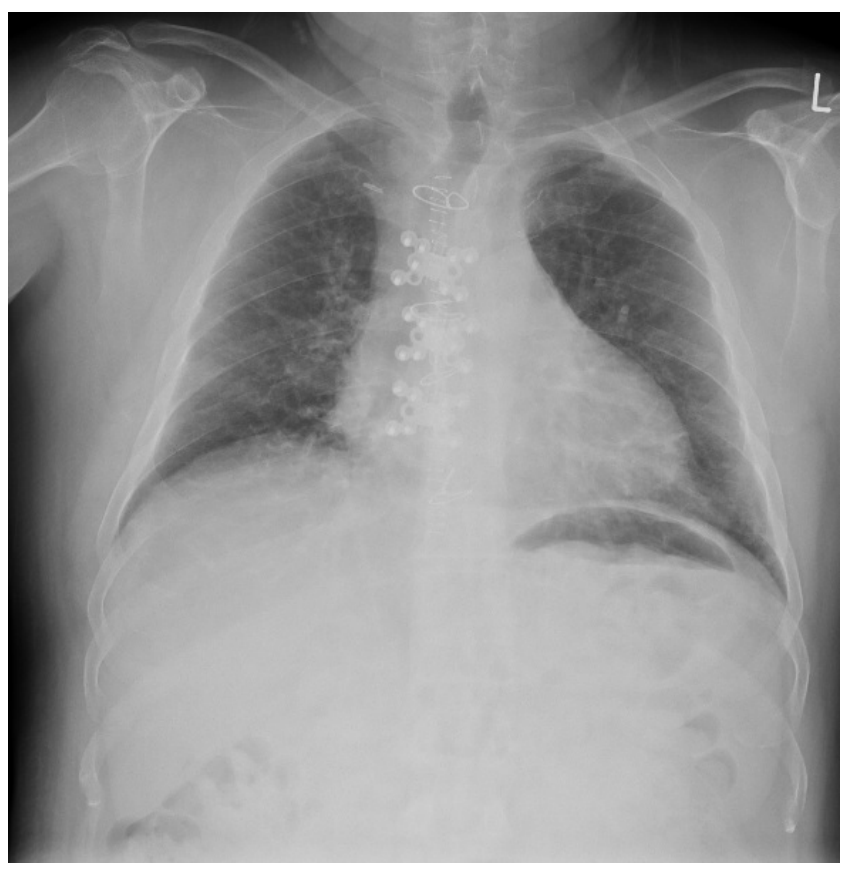

Figure 3: Postoperative chest X-ray showing union and fixation of sternum with titanium sternal fixation system highlighted the risk of devascularizing the sternum as an independent risk factor for sternal wound infection development ${ }^{[7]}$. With improving techniques of skeletonising the internal thoracic arteries however, many other studies have shown that there is no increased risk of BITA over single internal thoracic artery even in diabetic patients regardless of whether the surgery was on-pump or off-pump ${ }^{[8-11]}$.

Another risk factor for sternal dehiscence is poor sternal closure. Sternal closure stability plays a pivotal role in preventing this. Our patient underwent a modified Robicsek closure which is described as sternal closure technique that provides the greatest stability ${ }^{[12]}$. This consists of placing interlocking steel wires parasternal bilaterally and then including them in transverse sternal wires providing stability against vertical and horizontal forces.

Poor glycemic control in diabetics has also been identified as an independent risk factor for sternal dehiscence. Optimisation of preoperative levels of $\mathrm{HbA} 1 \mathrm{c}$ and blood glucose significantly reduced the rate of sternal wound complications in patients undergoing $\mathrm{CABG}^{[13]}$.

Sternal non-union is defined as sternal pain with clicking, instability, or both for more than 6 months in the absence of infection as present in outpatient. The use of plating for sternal non-union is relatively new. Hendrickson et al. ${ }^{[14]}$ first described its use in a case series of 6 patients with debilitating pain who reported improved quality of life post-plating with radiological evidence of fully healed sternotomies on follow up. Two patients developed bursae which settled on removal of the plates. Since then, multiple instances of sternal plate fixation have been used in the literature. A recent pilot study even advocated its use for primary closure of the sternum ${ }^{[15]}$.

Vos et al. ${ }^{[16]}$ conducted a retrospective analysis of patients with sternal dehiscence and compared outcomes of standard repair (steel wire cerclage and pectoralis muscle reconstruction) vs. titanium plating. The sternal plating group had greater sternal stability compared to the standard closure.

Kim et al. ${ }^{[17]}$ conducted a similar review of their patients. In their cohort of 2,769 patients, 36 patients developed deep sternal wound complications and 17 underwent titanium plate fixation following debridement of the sternum. Almost half of the patients who underwent plating were diabetic $(n=8)$. Eight patients had undergone conservative therapy (vacuum dressings and soft tissue debridement) prior to internal fixation 
with a titanium plate. One patient died following multiorgan failure secondary to mediastinitis that was present prior to plating with 2 requiring wound revisions due to aseptic wound dehiscence confined to the soft tissue. Another patient contracted tuberculosis and warranted an extended in-hospital stay. They concluded that rigid plate sternal fixation was a good option particularly for patients who require aggressive sternal resection.

The titanium plates also cost more than the other traditional methods of management including irrigation debridement and rewiring. However, considering its effectiveness, the shortened postoperative stay, improved outcomes and reduced readmission rates may reap its benefits.

Given the improvements in cardiac surgical techniques, sternal non-union remains an uncommon complication, albeit with significant morbidity. A larger multicentre trial may be warranted to verify its benefits over other modalities.

In conclusion, sternal fixation is a viable method to treat sternal malunion. Larger studies are needed to highlight its benefits compared to conventional therapy.

\section{DECLARATIONS}

\section{Authors' contributions}

Writing: S.S.A. Singh

Reviewing, editing, supervision: M. Capoccia, K. Deep, N. Al-Attar

\section{Financial support and sponsorship}

None.

\section{Conflicts of interest}

There are no conflicts of interest.

\section{Patient consent}

Verbal and written consent was obtained at time of surgery.

\section{Ethics approval}

Ethical approval was not needed as this was an FDA and CE-mark approved device that had been used for treatment of sternal non-union (FDA $510 \mathrm{k}$ number: K093 772).

\section{REFERENCES}

1. Tavilla G, van Son JA, Verhagen AF, Lacquet LK. Modified Robicsek technique for complicated sternal closure. Ann Thorac Surg 1991;52:1179-80.
2. Serruys PW, Morice MC, Kappetein AP, Colombo A, Holmes DR, Mack MJ, Ståhle E, Feldman TE, van den Brand M, Bass EJ, Van Dyck N, Leadley K, Dawkins KD, Mohr FW; SYNTAX Investigators. Percutaneous coronary intervention versus coronaryartery bypass grafting for severe coronary artery disease. $N$ Engl $J$ Med 2009;360:961-72.

3. Taggart DP. Bilateral internal mammary artery grafting: are BIMA better? Heart 2002;88:7-9.

4. Taggart DP, Aratari C, Wong P, Paul EA, Wright JE. Applicability of intermittent global ischemia for repeat coronary artery operations. $J$ Thorac Cardiovasc Surg 1996;112:501-7.

5. Yi G, Shine B, Rehman SM, Altman DG, Taggart DP. Effect of bilateral internal mammary artery grafts on long-term survival: a meta-analysis approach. Circulation 2014;130:539-45.

6. Nasso G, Coppola R, Bonifazi R, Piancone F, Bozzetti G, Speziale G. Arterial revascularization in primary coronary artery bypass grafting: direct comparison of 4 strategies--results of the Stand-in-Y Mammary Study. J Thorac Cardiovasc Surg 2009;137:1093-100.

7. Grossi EA, Esposito R, Harris LJ, Crooke GA, Galloway AC, Colvin SB, Culliford AT, Baumann FG, Yao K, Spencer FC. Sternal wound infections and use of internal mammary artery grafts. $J$ Thorac Cardiovasc Surg 1991;102:342-6; discussion 346-7.

8. De Paulis R, de Notaris S, Scaffa R, Nardella S, Zeitani J, Del Giudice C, De Peppo AP, Tomai F, Chiariello L. The effect of bilateral internal thoracic artery harvesting on superficial and deep sternal infection: The role of skeletonization. J Thorac Cardiovasc Surg 2005;129:536-43.

9. Ogawa S, Okawa Y, Sawada K, Goto Y, Yamamoto M, Koyama Y, Baba H, Suzuki T. Continuous postoperative insulin infusion reduces deep sternal wound infection in patients with diabetes undergoing coronary artery bypass grafting using bilateral internal mammary artery grafts: a propensity-matched analysis. Eur J Cardiothorac Surg 2016;49:420-6.

10. Hirotani T, Kameda T, Kumamoto T, Shirota S, Yamano M. Effects of coronary artery bypass grafting using internal mammary arteries for diabetic patients. J Am Coll Cardiol 1999;34:532-8.

11. Jeong DS, Sung K, Lee YT, Ahn JH, Carriere KC, Kim WS, Park PW. Pure bilateral internal thoracic artery grafting in diabetic patients with triple-vessel disease. Ann Thorac Surg 2015;100:2190-7.

12. Schimmer C, Reents W, Elert O. Primary closure of median sternotomy: a survey of all German surgical heart centers and a review of the literature concerning sternal closure technique. Thorac Cardiovasc Surg 2006;54:408-13.

13. Hillis LD, Smith PK, Anderson JL, Bittl JA, Bridges CR, Byrne JG, Cigarroa JE, Disesa VJ, Hiratzka LF, Hutter AM Jr, Jessen ME, Keeley EC, Lahey SJ, Lange RA, London MJ, Mack MJ, Patel MR, Puskas JD, Sabik JF, Selnes O, Shahian DM, Trost JC, Winniford MD. 2011 ACCF/AHA guideline for coronary artery bypass graft surgery: a report of the american college of cardiology foundation/american heart association task force on practice guidelines. Circulation 2011;124:e652-735.

14. Hendrickson SC, Koger KE, Morea CJ, Aponte RL, Smith PK, Levin LS. Sternal plating for the treatment of sternal nonunion. Ann Thorac Surg 1996;62:512-8.

15. Bennett-Guerrero E, Phillips-Bute B, Waweru PM, Gaca JG, Spann JC, Milano CA. Pilot study of sternal plating for primary closure of the sternum in cardiac surgical patients. Innovations (Phila) 2011;6:382-8.

16. Vos RJ, Jongbloed L, Sonker U, Kloppenburg GTL. Titanium plate fixation versus conventional closure for sternal dehiscence after cardiac surgery. Thorac Cardiovasc Surg 2017;65:338-42.

17. Kim WK, Kim JB, Kim GS, Jung SH, Choo SJ, Chung CH, Lee JW. Titanium plate fixation for sternal dehiscence in major cardiac surgery. Korean J Thorac Cardiovasc Surg 2013;46:279-84. 